\title{
MARIE JOQUEVIEL-BOURJEA, Dany Laferrière Écrirevoir
}

\section{Roberto Ferraroni}

\section{CpenEdition \\ Journals}

\section{Edizione digitale}

URL: http://journals.openedition.org/studifrancesi/16811

DOI: 10.4000/studifrancesi.16811

ISSN: 2427-5856

\section{Editore}

Rosenberg \& Sellier

\section{Edizione cartacea}

Data di pubblicazione: 1 juillet 2019

Paginazione: 204-205

ISSN: 0039-2944

\section{Notizia bibliografica digitale}

Roberto Ferraroni, «MARIE JOQueVIEL-BOURJEA, Dany Laferrière Écrirevoir», Studi Francesi [Online], 187 (LXIII I I) | 2019, online dal 01 juillet 2019, consultato il 25 janvier 2021. URL: http://journals.openedition.org/ studifrancesi/16811 ; DOI: https://doi.org/10.4000/studifrancesi.16811

Questo documento è stato generato automaticamente il 25 janvier 2021.

\section{(c) (†)}

Studi Francesi è distribuita con Licenza Creative Commons Attribuzione - Non commerciale - Non opere derivate 4.0 Internazionale. 


\title{
MARIE JOQUEVIEL-BOURJEA, Dany Laferrière Écrirevoir
}

\author{
Roberto Ferraroni
}

\section{NOTIZIA}

MARIE JOQUEVIEL-BOURJEA, Dany Laferrière Écrirevoir, Paris, Hermann Éditeurs, 2017, 97 pp.

1 Marie Joqueviel-Bourjea, esperta di letteratura francese del Xx e XxI secolo, propone un breve saggio sull'opera di uno degli autori haitiani contemporanei più prolifici $\mathrm{e}$ premiati: Dany Laferrière. I suoi studi di poesia e il grande interesse per la pittura permeano questo volume fin dal titolo: la parola "écrirevoir" è il risultato della fusione di due termini che provengono proprio da questi due ambiti. "Écrire" si ricollega alla produzione poetica, alla scrittura, mentre "voir" richiama chiaramente l'arte pittorica. La scelta di utilizzare questa parola inventata è dettata dall'idea che l'opera di Laferrière sia il prodotto non soltanto della sapiente mano di un esperto di prosa, ma anche il frutto della straordinaria abilità del romanziere haitiano nello scrivere frasi che suonano come versi, intervallandole con immagini dipinte a parole. Nonostante la costanza dello scrittore nel negare la sua natura di poeta, Bourjea mette in luce in questo saggio come ogni pagina, ogni paragrafo, ogni frase dell'autore siano in realtà intrisi di profonda poesia. La fluidità della sua prosa, la scelta delle parole, la musicalità dei suoi periodi sembrano smentire le sue dichiarazioni, probabilmente dettate da un eccesso di modestia.

2 Ancora più evidente, anche a un lettore inesperto, è la straordinaria capacità di Laferrière di creare veri e propri dipinti attraverso le parole, immagini che si presentano come fotografie. Tuttavia non si tratta soltanto di descrizioni paesaggistiche; al contrario si trovano spesso dei fermimmagine che catturano letteralmente momenti di vita reale ad Haiti e dei ritratti degli abitanti dell'isola caraibica. Questa peculiarità è particolarmente evidente in Pays sans chapeau, romanzo del 1996, caratterizzato dall'alternanza di capitoli dedicati al Pays réel e al Pays rêvé: 
tutte le parti dedicate al pays réel presentano "fotografie" così dettagliate del mondo haitiano che, leggendole, il lettore si sente totalmente immerso in una realtà che, con ogni probabilità, non ha mai visto né vissuto dal vivo.

3 La struttura del volume risulta volutamente simmetrica, con un préambule e una clausule che rispettivamente aprono e chiudono il saggio. Si tratta di due brevi capitoli in cui Bourjea lascia parlare il suo io di lettrice, mettendo da parte le sue conoscenze da specialista. Mentre nei capitoli centrali offre al lettore un'analisi tecnica della scrittura di Laferrière, in queste poche pagine confida la sua opinione sull'opera dello scrittore, il suo approccio alla lettura e il percorso che l'ha portata alla stesura del saggio. Subito dopo il préambule è inserito un capitolo dedicato a "Poésie \& Peinture", speculare al penultimo capitolo "Photographie et Cinéma", le diverse arti che si intrecciano fino a confondersi nella scrittura dell'autore haitiano. I tre capitoli che li separano, quelli centrali, sono invece le sezioni più strettamente tecniche, dedicate a un'attenta analisi dello stile di Laferrière.

4 Il saggio di Bourjea non lascia dubbi riguardo il suo interesse e la sua preparazione sull'opera di Laferrière. L'intero volume è un susseguirsi di esempi estrapolati da molti dei romanzi che costituiscono la vasta produzione letteraria dell'autore, tutti volti a sottolineare le peculiarità che lo rendono un unicum nel panorama letterario haitiano, pur lasciando trasparire i tratti che lo accomunano a tanti scrittori originari di questa terra che, come lui, hanno conosciuto prima la vita sull'isola e in un secondo tempo la vita in esilio; una vita lontana dalla propria patria, fatta di ricordi e di quella lotta costante tra il desiderio di tornarvi e la consapevolezza delle ragioni che li hanno portati ad allontanarsi, consci del fatto che proprio le difficoltà incontrate sono probabilmente ciò che più di tutto li hanno resi importanti scrittori di successo, facendo emergere e nutrendo la loro vena creativa. 